\title{
Concesiones forestales, exclusión y sustentabilidad. Lecciones desde las comunidades de la Sierra Norte de Oaxaca
}

\author{
Mario E. Fuente Carrasco y David Barkin
}

Los esfuerzos comunitarios que enfrentan los conflictos económicos distributivos generadores de exclusión son praxis identificadas como ejemplos de una ética concreta. Este trabajo recupera la experiencia campesina de la Sierra Norte de Oaxaca durante los procesos de exclusión que implicaron el otorgamiento de las concesiones forestales. Las praxis se muestran como lecciones en la construcción de procesos de apropiación social de la naturaleza con una mayor responsabilidad social y ambiental, pero también como estrategias vigentes para esca-

PALABRAS CLAVE: comunalidad, sustentabilidad, conflictos distributivos, concesiones, praxis campesina

Forest Concessions, Exclusion and Sustainability. Lessons from the Communities of the Sierra Norte de Oaxaca

Community efforts to overcome distributive economic conflicts are a way to challenge directly processes of social exclusion. These practices are specific examples of a concrete ethos. Peasants from the Sierra Norte in Oaxaca were excluded by the award of concessions to exploit the forests to private companies. The analysis examines the lessons learned and their application in subsequent efforts to transform the social appropriation of nature into a process that is both socially and environmentally responsible; these efforts also became a strategy for escaping from a new dependency on the globalized market.

KEYWORDS: communality, sustainability, distributive conflicts, concessions, rural praxis

Mario E. Fuente Carrasco: Instituto de Estudios Ambientales, Universidad de la Sierra Juárez, Sistema de Universidades Estatales de Oaxaca, Ixtlán de Juárez, Oaxaca, México fuente@juppa.unsij.edu.mx

David Barkin: Departamento de Producción Económica, Universidad Autónoma Metropolitana, Unidad Xochimilco, México, Distrito Federal

barkin@correo.xoc.uam.mx

Desacatos, núm. 37, septiembre-diciembre 2011, pp. 93-110

Recepción: 1 de septiembre de 2009 / Aceptación: 13 de marzo de 2011 
Eliminar la exclusión es la única manera de alcanzar la equidad. Y la equidad es la marca de la justicia.

Luis Villoro.

\section{INTRODUCCIÓN}

$\mathrm{D}$ urante las últimas tres décadas los países industrializados han intensificado sus estrategias geopolíticas para aumentar la acumulación del capital, entre ellas las orientadas a facilitar el acceso y la apropiación de los recursos genéticos, hídricos y mineros, y de fuentes de energía - petróleo, viento, agrocombustible-. En ciertos casos, estos procesos se enfrentan a algunas limitantes: gran parte de estos recursos - como en el caso de México- están ubicados en territorios de propiedad federal o en comunidades agrarias de propiedad social - ejidal o comunal-. Con una política económica subordinada a los procesos de integración económica internacional, y ante los candados supervivientes del artículo 27 constitucional para limitar la intromisión de los intereses privados en la apropiación de los recursos naturales, la figura jurídica de las concesiones tiene un papel protagónico en la viabilidad de las citadas estrategias geopolíticas. Esta figura facilita la intrusión de los mecanismos del mercado en la propiedad social o federal bajo el efugio de priorizar el crecimiento económico. Así, las concesiones se colocan como uno de los ejes de las disputas sobre la orientación del modelo de desarrollo del país.

Estos procesos geopolíticos ocurren en el contexto de la racionalidad económica emergida del proyecto civilizatorio de la modernidad capitalista en su versión "americanizada." ${ }^{1}$ Desde esta racionalidad, además de mercantilizar a "la naturaleza, las conductas

\footnotetext{
${ }^{1}$ Se hace referencia al proceso histórico, acaecido principalmente en Europa, que permite el nacimiento y desarrollo del capitalismo y de sus instituciones. Se enfatiza el sesgo en lo que Echeverría (2008) llamó modernidad en su versión anglosajona o "americanizada".
}

ecológicas y los valores culturales" (Leff, 2004: 197), se identifica al crecimiento económico como sinónimo de progreso. Hay una subestimación de los "daños colaterales": se agudizan los procesos de exclusión social y disminución de la resiliencia de los ecosistemas, y se prescinde de la justicia distributiva como un atributo ético de la sustentabilidad (Seara, 1995: 20). En este contexto, y dada la abdicación del Estado mexicano de su responsabilidad constitucional de buscar una distribución justa de la riqueza, cabe hacer una pregunta: ¿cómo es posible que desde la sociedad civil se favorezca la construcción de una responsabilidad $^{2}$ que impulse una mayor articulación de la justicia distributiva como atributo de la sustentabilidad? No hay respuesta única, de ahí la idea zapatista de construir un mundo donde quepan muchos mundos. En este documento se exploran algunas de estas respuestas en geografías y calendarios muy específicos. Se describen las réplicas de comunidades con ascendencia de la cultura zapoteca ante la instrumentación del modelo de las concesiones forestales otorgadas por el Estado mexicano a empresas privadas y paraestatales de 1950 a 1980. El referente empírico es aportado por algunas comunidades agrarias del distrito de Ixtlán de Juárez de la Sierra Norte de Oaxaca.

El tratamiento desde esta experiencia enfatiza la posibilidad de ligazón y construcción de una sustentabilidad que incorpore los valores de equidad y justicia distributiva desde las instituciones de la sociedad rural con ascendencia de la cultura mesoamericana —zapoteca-, pero al mismo tiempo identifica dichas praxis como estrategias alternas a la racionalidad económica e instituciones emanadas del proyecto civilizatorio occidental en su versión americanizada. Esta ligazón se muestra como producto de un enfrentamiento del grupo excluido ante

\footnotetext{
${ }^{2}$ Se toma el concepto de responsabilidad "en el marco de un dilema provocado por la incapacidad de los Estados para cubrir las demandas de sociedades... surge, precisamente, cuando termina de incubarse una crisis de responsabilidad del Estado como consecuencia de una preeminencia del mercado que le arrebata, literalmente, la competencia" (Morales, 2006: 12).
} 
el poder, desde el cual se justifica e impulsa una acumulación concentradora de los ingresos, la exclusión social y el deterioro ambiental. Por ello, la dimensión de la interculturalidad se constituye en un componente fundamental. Se argumenta, desde una hipótesis de trabajo, que las comunidades rurales herederas del proyecto civilizatorio mesoamericano ${ }^{3}$ poseen un alto grado de interculturalidad, lo cual aporta la posibilidad de arreglos alternos a los emanados del proyecto civilizatorio de la modernidad americanizada (véase figura 1). Con ello se abren diferentes racionalidades y criterios en la distribución de los beneficios y las cargas desprendidas de los procesos de apropiación social de la naturaleza con una mayor articulación entre la responsabilidad social y la ambiental.

\section{DEL ENFOQUE UTILITARISTA A LA ÉTICA CONCRETA}

Desde una perspectiva analítica, el trabajo procura distanciarse del enfoque utilitarista que prevalece en la racionalidad económica vigente. ${ }^{4}$ En la comunidad anglosajona, con Rawls y Sen, se plantea la necesidad de recuperar la dimensión de la filosofía política con que nació la economía como ciencia y base de la política pública. En este entorno analítico, la investigación partió de la glosa dada por Rawls (1995: 21) al referir que el objetivo de la justicia está vinculado con el modo en que las grandes instituciones sociales distribuyen los derechos y deberes fundamentales, así como las oportunidades económicas y condiciones sociales en los diversos sectores de la sociedad. De este autor se comparte la crítica al

\footnotetext{
${ }^{3}$ Se refiere al "México profundo" que describe Bonfil Batalla (2005) dentro del contexto del proyecto civilizatorio mesoamericano.

${ }^{4}$ No es mera coincidencia la corriente filosófica francesa Movimiento Anti-utilitarista de Ciencias Sociales (MAUss, por sus siglas en francés), expuesta en su revista, Revue MaUss, que tiene un largo historial de publicación, incluyendo una gama amplia de pensadores de líneas congruentes con las plasmadas en el presente trabajo.
}

utilitarismo y la importancia de trascender la evaluación de la concepción de justicia por su papel distributivo, pero se matizan y acotan otros aspectos, como los siguientes:

a) La distribución no se remite sólo a los ingresos y los beneficios generados a través de transferencias, subsidios e impuestos, sino más bien se enfoca primordialmente en los procesos productivos.

b) El tema de los derechos de propiedad se considera fundamental en la definición y orientación de las reglas de distribución. Para Rawls hay dos opciones: la privada y la estatal. En este trabajo se destaca una tercera opción: la social (por ejemplo, la tenencia de tierra comunal).

c) La incorporación de la dimensión de la interculturalidad, y de "otras" instituciones - por ejemplo, la comunalidad-como ejes de análisis en la construcción de otro "contrato social" ${ }^{5} \mathrm{y}$ de otros mundos posibles.

d) La distinción entre dos niveles de análisis y su interrelación. Por una parte de la relación de las "grandes instituciones" del Estado hacia un segmento específico de la sociedad mexicana, por ejemplo la sociedad rural con ascendencia en la cultura indígena. El otro nivel estaría representado en las relaciones al interior de los diferentes grupos de la sociedad mexicana, por ejemplo el grado de comunalidad dado al interior de las comunidades agrarias. El artículo se enfoca sólo al primer punto. ${ }^{6}$

\footnotetext{
${ }^{5}$ La metáfora del pacto o "contrato social" se presenta como un discurso de la filosofía política de la modernidad encaminado a explicar la transición del "estado de naturaleza" hacia la posibilidad de la fundación de la sociedad. En sus inicios se abre el debate con Hobbes, Locke y Rousseau. El concepto de contrato social no agota la complejidad social, pero se retoma por su idea original que trata de registrar la situación que prevalecería entre los hombres a falta de un consenso que resguarde la convivencia. Aspecto ligado, ahora, con el tema del consenso y la (in)justicia. ${ }^{6} \mathrm{El}$ tema de la exclusión "interna" es un aspecto de alto interés de la ciencia política, ya que permite plasmar las luchas internas entre los individuos o subgrupos de la comunidad. En las comunidades abordadas en este artículo hay una heterogeneidad de
} 
Lo expresado en los puntos anteriores permite incorporar guías analíticas para establecer una ruptura frente al enfoque utilitarista, pero también da la pauta para la diferenciación del abordaje del tema de la justicia desde el enfoque de la ética normativa al de la ética concreta, esto es, la identificación de las praxis sociales como elementos epistémicos. Este señalamiento evidencia el contexto diferente en que se discute el tema de la justicia en los países del norte y en los del sur. En estos últimos hay una percepción de su ausencia.

Con Rawls se acentúa el enfoque normativo acotado al modelo del proyecto civilizatorio occidental para "evaluar" el grado de imperfecciones de la sociedad. En contraparte, desde los países del sur, se hace explícito el asunto de la realización de la justicia a partir de la citada percepción de la ausencia real de justicia para proyectar lo que podría remediarla, como acciones que permitan su aplicación. Así, el enfoque de la ética concreta intenta aproximarnos a la noción de justicia a través de su vía negativa, tal como lo apunta Villoro (2007: 15): "En nuestra realidad social no son comunes comportamientos consensuados que tengan por norma principios de justicia incluyentes de todos los sujetos; se hace patente su ausencia". Por ello, Villoro incorpora la idea del "poder injusto". Es decir, no se trata sólo de expresar formalmente los conceptos y principios de justicia como algo ya dado (el deber ser):

Las expresiones formalmente negativas de los derechos humanos universales establecen en el "coto vedado" la vigencia de derechos que deben de realizarse en toda sociedad. Forman parte, por tanto, de una ética concreta, que establece los límites, no de normas que deben cumplirse, sino de su cumplimiento efectivo en hechos históricos (Villoro, 2007: 32).

manifestaciones en este tema respecto de, por ejemplo, los procesos de inclusión/exclusión desde la perspectiva de género, edad —niños, jóvenes-, la condición de comunero o ciudadano, situación de residencia local, entre otros. Otero (2004) plantea en este sentido que a una mayor inclusión y despliegue de procesos democráticos se favorecerá una mayor capacidad de la comunidad — formación político-cultural- para negociar su relación con el Estado.
Para propiciar un contenido a esta ética concreta, en la que se vincula el tema de la justicia distributiva en la sustentabilidad, se atienden dos niveles analíticos. En las primeras secciones se quiere evidenciar la necesidad de la deconstrucción del contenido del discurso institucionalizado de desarrollo sostenible como derivado de la racionalidad económica ortodoxa. En este aspecto, los campos de la economía ecológica y de la ecología política constatan las anomalías paradigmáticas de su discurso. El segundo nivel se emprende a partir de la configuración de la praxis específica y concreta de las comunidades agrarias de la Sierra Norte de Oaxaca, es decir, como una aproximación a la noción de justicia no desde una postura normativa, sino desde el punto de vista de su cumplimiento efectivo en hechos históricos para "escapar del poder injusto", como señala Villoro (2007).

\section{EL DESARROLLO SUSTENTABLE DESDE LA ORTODOXIA}

Desde su entrada en el escenario internacional y su institucionalización en la Cumbre de Río en 1992, el término de desarrollo sostenible ha sido uno de los más prolíficos y polémicos usados en los ámbitos académico y político. La satisfacción de las necesidades de las generaciones presentes sin detrimento de las futuras se ha convertido en la acepción y aspiración más convencional. Ante la amplitud de opciones sobre la orientación y contradicciones para la instrumentación de tal aspiración, predomina un consenso relativo en la afirmación de que su cumplimiento implica mantener el crecimiento económico, pero internalizando los costos socioculturales y ambientales.

Hay tres modelos ortodoxos de desarrollo sostenible. Martínez Alier (2004) señala los primeros dos: a) "el evangelio a la ecoeficiencia", que representa un enfoque economicista, tecnológico y antropocéntrico, cuyo sustento académico se basa principalmente en la economía ambiental y la ecología industrial, y b) el "culto a lo silvestre", que se construye desde una 


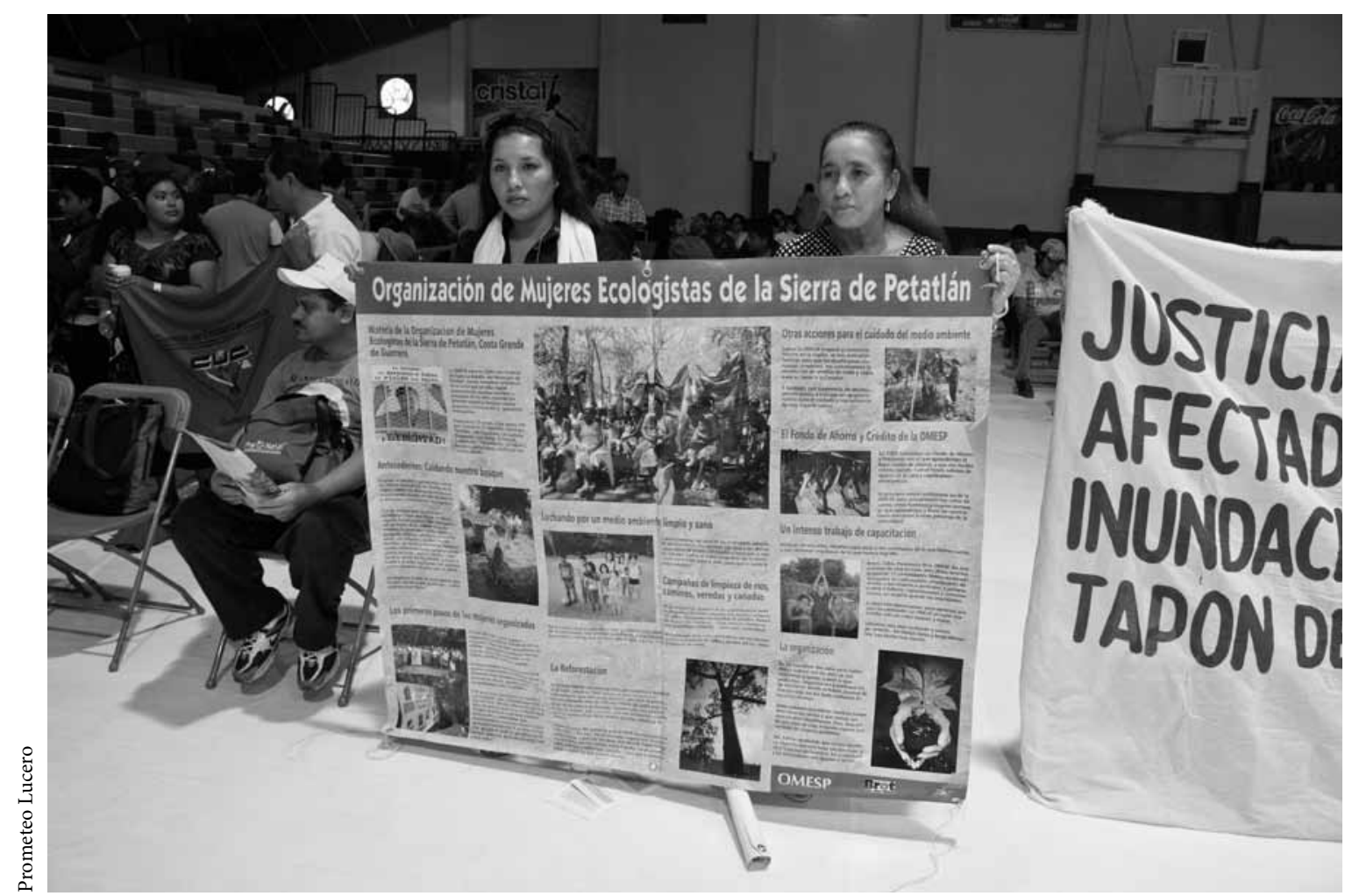

Protestas durante la Conferencia de las Naciones Unidas sobre el Cambio Climático (cop 16) en Cancún, Quintana Roo, 2010.

postura ecocéntrica a partir de los fundamentos de la ecología profunda y la biología conservacionista. Foladori (2005) identifica otra vertiente: c) la sustentabilidad "social-puente", impulsada por organismos multilaterales como el Banco Mundial y que coloca al combate de la pobreza del Tercer Mundo como la solución al trinomio "pobreza-población-degradación ambiental”. Esta vertiente está apoyada en los planteamientos del neoinstitucionalismo.

A pesar de las aparentes diferencias, estas visiones ostentan una concepción común: la idea de una sociedad como "bloque" homogéneo. A lo sumo, sólo se reconoce la diferencia entre "norte" y "sur", pero se asocia con problemas de "subdesarrollo". Estos discursos evaden la identificación y la relación que existe entre racionalidad económica del crecimiento ilimitado respecto del aumento de la desigual distribución de la riqueza y la generación del conflicto ambiental. Su noción es acotada a los marcos que imponen las instituciones emergidas del proyecto de modernidad occidental: el individualismo liberal, la propiedad privada, la democracia representativa, el mercado autorregulado y el crecimiento económico como progreso.

Con la irrupción de Walras (1834-1910) como uno de los fundadores de la economía neoclásica, se enfatiza la valoración ética del liberalismo individual, pero no la de la justicia y la equidad. Ya no hay conflicto de clases, sino la confluencia en el mercado de dos identidades que se mueven en el mismo plano de libertad e igualdad: ofertantes y demandantes. El concepto de valor-trabajo se elimina y el mercado es consagrado como el mecanismo más eficiente para resolver el problema de la asignación de recursos. Con ello se desvanece la relación que guardan la justicia y la equidad con los temas de derechos 
de la propiedad, poder y distribución de la renta, tal como había sido descubierto por la corriente marxista. La expresión monetaria definida - en el precio- se consagra como el lenguaje de valoración de todo, incluyendo la salud o la naturaleza. Lo mismo se extiende al tema ambiental, los economistas de recursos y los economistas ambientales: "abordan interrogantes sobre la asignación eficiente de los recursos, dejando la distribución inicial de los recursos como algo estipulado, que no debería de cuestionarse" (Costanza et al., 1999: 37). Sin embargo, la supuesta eficiencia de la asignación a través del mercado $^{7}$ no garantiza ni la justicia (Sen, 1997) ni la sustentabilidad ambiental, sino su contrario (Barkin, 1998): abordar de manera aislada el tema de la sustentabilidad sin hacer referencia al problema de la distribución es una limitante analítica, pero también una estrategia del poder político vinculado al interés del poder económico.

\section{LA DIMENSIÓN ÉTICA DE LA SUSTENTABILIDAD}

En Latinoamérica, las prácticas sociales que contribuyen a revertir los procesos de exclusión representan propuestas epistémicas fundamentales en la construcción de una racionalidad ambiental, por ello el tema de la justicia distributiva -económica, ambiental, social o cultural- sigue siendo un imperativo categórico en el tema de la construcción de la sustentabilidad. Las prácticas sociales que enfrentan a los procesos de exclusión son identificadas, desde esta perspectiva, como praxis, es decir, como saberes puestos en práctica, pero a su vez como la práctica política emancipadora que le dará un estatuto

\footnotetext{
${ }^{7}$ Una estrategia es resolver las "fallas del mercado", es decir, la internalización de las externalidades. Actualmente, en esta tesitura se ha incluido el tema de la "responsabilidad social corporativa" como otra forma de involucrar a las empresas en su preocupación ambiental, pero sin afectar el fin último de la empresa: maximizar las ganancias. También se promueven los programas de "pagos por servicios ambientales".
}

epistemológico a la teoría (Sánchez, 2003). Este tipo de práctica presenta atributos epistémicos comunes a los descritos por otros autores en la noción de "diálogo de saberes" (Leff, 2006) o "sabidurías tradicionales" (Toledo y Barrera, 2008).

En esta perspectiva, el tratamiento del tema de la lucha contra la exclusión social y el esfuerzo para minimizar los conflictos distributivos están vinculados con la promoción de la equidad, la defensa de los derechos de propiedad social y la gestión sustentable de los recursos naturales. Los campos heterodoxos de la economía ecológica y la ecología política hacen explícito este reconocimiento. Desde éstos, se exige el desarrollo de propuestas metodológicas que incorporen un juicio ecológico sobre las posibilidades - economía neguentrópica- y limitantes biofísicas inherentes a la idea de un crecimiento económico, pero también la de un juicio de tipo ético e histórico sobre las reglas de distribución de los costos y beneficios derivados de los procesos de apropiación social de la naturaleza (Burkett, 2006; Barkin, 2008; Fuente, 2008; Leff, 2008; Martínez Alier, 2004). La categoría de conflictos ecológicos distributivos contribuye a la comprensión de los problemas relacionados con las externalidades ambientales y las praxis sociales que surgen como respuestas ante los conflictos distributivos:

\footnotetext{
para dar cuenta de la carga desigual de los costos ecológicos y sus efectos en la variedad del ambientalismo emergente, incluyendo los movimientos de resistencia al neoliberalismo, de compensación por daños ecológicos y de justicia ambiental... comprende pues los procesos extraeconómicos (ecológicos y políticos) que vinculan a la economía ecológica con la ecología política, en analogía con el concepto de distribución en economía (Leff, 2004: 256).
}

Desde este enfoque, en la investigación se destacan tres implicaciones analíticas: a) la relación de los conflictos distributivos económicos con los ambientales; b) la inscripción del principio de la justicia distributiva como un atributo fundamental de la sustentabilidad, y c) la participación social en la construcción de 
nichos de sustentabilidad como contribución epistémica y de un diálogo de saberes.

\section{LAS COMUNIDADES FORESTALES DE LA SIERRA NORTE DE OAXACA COMO REFERENTE EMPÍRICO}

Frente a las instituciones emergidas del proyecto civilizatorio occidental en su modalidad americanizada, diversos grupos campesinos con ascendencia de la cultura mesoamericana han optado por revalorar y transformar sus instituciones como estrategias alternas a la proletarización y a los procesos de exclusión. El caso de la silvicultura comunitaria mexicana ${ }^{8}$ es un ejemplo de esta lucha constante. $\mathrm{Al}$ respecto, México destaca a nivel mundial por ocupar el primer lugar en empresas forestales comunitarias (Bray, Merino y Barry, 2007). Del territorio nacional forestal, $80 \%-55.3$ millones de hectáreas- está en 8500 comunidades agrarias de propiedad ejidal y comunal, con una población estimada de más de 12 millones de habitantes (Conafor, 2008). Adicionalmente, en los bosques mexicanos se presenta una correlación alta entre la diversidad cultural y biológica: al menos 28 millones de estas hectáreas están ubicadas en pueblos indígenas y se caracterizan no sólo por su diversidad étnica sino también por su biodiversidad natural silvestre y domesticada, como los recursos bióticos vinculados con los agrosistemas (véase por ejemplo la variedad de maíces nativos) (Boege, 2009).

A raíz de la reforma agraria cardenista, producto de las victorias revolucionarias, estas comunidades campesinas obtuvieron la posibilidad de la posesión del territorio en función de la decisión del Estado mexicano. A pesar de esta dotación, el gobierno retuvo la facultad de otorgar la explotación de los recursos forestales a entidades externas o de ponerlas

\footnotetext{
${ }^{8}$ Existe abundante literatura sobre las implicaciones y dimensiones del manejo forestal comunitario en México. Destacan, por ejemplo, las aportaciones de Bray (1995), Bray et al. (2003), Bray, Merino y Barry (2007) y Klooster (2000).
}

en veda. Esto ocurrió en casi todas las comunidades forestales, incluyendo los pueblos de la Sierra Norte de Oaxaca. Como consecuencia, estos territorios y sus recursos naturales han sido motivo de una disputa constante entre sus pobladores y el Estado mexicano. En el fondo de la querella está la orientación del proyecto de nación que el grupo dirigente ha querido imponer y las réplicas campesinas ante tal proyecto. La historia es larga y continuará en los próximos años debido a las características excluyentes del modelo económico vigente. En este artículo se aborda un aspecto histórico específico: las respuestas campesinas ante el otorgamiento de las concesiones forestales dadas por el Estado a empresas públicas o privadas en territorios comunales y ejidales durante la segunda mitad del siglo pasado, pero con gran actualidad en el nuevo contexto de integración económica internacional. ${ }^{9}$ En la práctica, las concesiones forestales representaron una "privatización" o "estatización" de la propiedad social. Fueron impulsadas por el gobierno mexicano para cubrir las demandas internas en materia de celulosa bajo la premisa de que las comunidades campesinas no eran capaces de tal encomienda. Surgieron confrontaciones que marcaron la historia de la silvicultura forestal mexicana, en la que se involucraron comunidades de diversos estados de la república.

La Sierra Norte de Oaxaca es una región heterogénea y compleja. Entre sus características destacan: a) una amplia gama de estudios de diversos aspectos de la relación entre la organización comunitaria y el aprovechamiento de sus recursos naturales; b) está cohabitada por comunidades con ascendencia zapoteca, mixe y chinanteca; c) sus procesos de apropiación son reconocidos nacional e internacionalmente como de alta responsabilidad ambiental; d) presenta alta biodiversidad registrada por organismos internacionales; e) proporciona servicios ambientales fundamentales para el estado y el país; f) sus pobladores

\footnotetext{
${ }^{9}$ De hecho, los conflictos están extendiéndose e intensificándose por una nueva etapa de explotación minera impulsada por el Estado mexicano en asociación con capital extranjero, fundamentalmente de origen canadiense.
} 
Cuadro 1. Población por localidad de las comunidades sujetas de estudio

\begin{tabular}{lccc}
\hline \multicolumn{1}{c}{ Comunidad agraria } & Fecha de resolución presidencial & Comuneros & Superficie (hectáreas) \\
\hline La Trinidad Ixtlán & 24 de noviembre de 1948 & 180 & 805 \\
\hline Santiago Xiacuí & 16 de noviembre de 1949 & 250 & 1680 \\
\hline Capulálpam de Méndez & 20 de agosto de 1952 & 330 & 4144 \\
\hline Santiago Comaltepec & 18 de diciembre de 1953 & 340 & 186 \\
\hline $\begin{array}{l}* \text { Datos aproximados } \\
\text { Fuente: Oficina de la Procuraduría Agraria de Ixtlán (diciembre de 2008). }\end{array}$
\end{tabular}

han mantenido la lucha por la defensa de sus recursos naturales - forestales, mineros, agua, genéticos—; g) ha sido utilizada por dependencias gubernamentales nacionales e internacionales como "ejemplo" de un manejo responsable conducente al desarrollo, y h) se encuentra, como toda la sociedad rural mexicana, ante los embates de las instituciones de corte neoliberal y en fuerte crisis de legitimidad. La defensa de comunitaria desde la categoría de comunalidad (Martínez Luna, 2010; Díaz, 2007). La comunalidad representa una contribución epistémica que da cuenta de procesos de apropiación de la naturaleza de una manera alterna a la visión ortodoxa y a las instituciones del proyecto civilizatorio occidental (véase figura 1). De la comunalidad se incorporan un conjunto de atributos institucionales comunitarios, como:

- La democracia participativa o directa, alimentada por el ejercicio cotidiano en la asamblea ciudadana, comunal y las diversas instancias de vigilancia. Es decir, en gran parte de estas comunidades se despliega la democracia directa - uso constante de la asamblea para informar acciones, toma de decisiones y la rendición de cuentas-, pero también la representativa. Ello contribuyó a que en Oaxaca las reformas en materia electoral integraran el sistema de normas consuetudinarias - "usos y costumbres" - para elegir a sus autoridades municipales (Hernández Díaz, 2007). Debe destacarse en este punto la relación entre esta democracia participativa y las acciones vinculadas con el tema ambiental (Mitchell, 2008).

- La organización del trabajo comunitario, que se desarrolla sin compensación monetaria pero ligado a otro tipo de valoraciones, como el desarrollo de prestigio local o de compromisos impuestos 
Figura 1. Modelo de contraste entre instituciones del proyecto civilizatorio de la modernidad americanizada y el derivado de la cultura mesoamericana en su articulación con instituciones de la Colonia

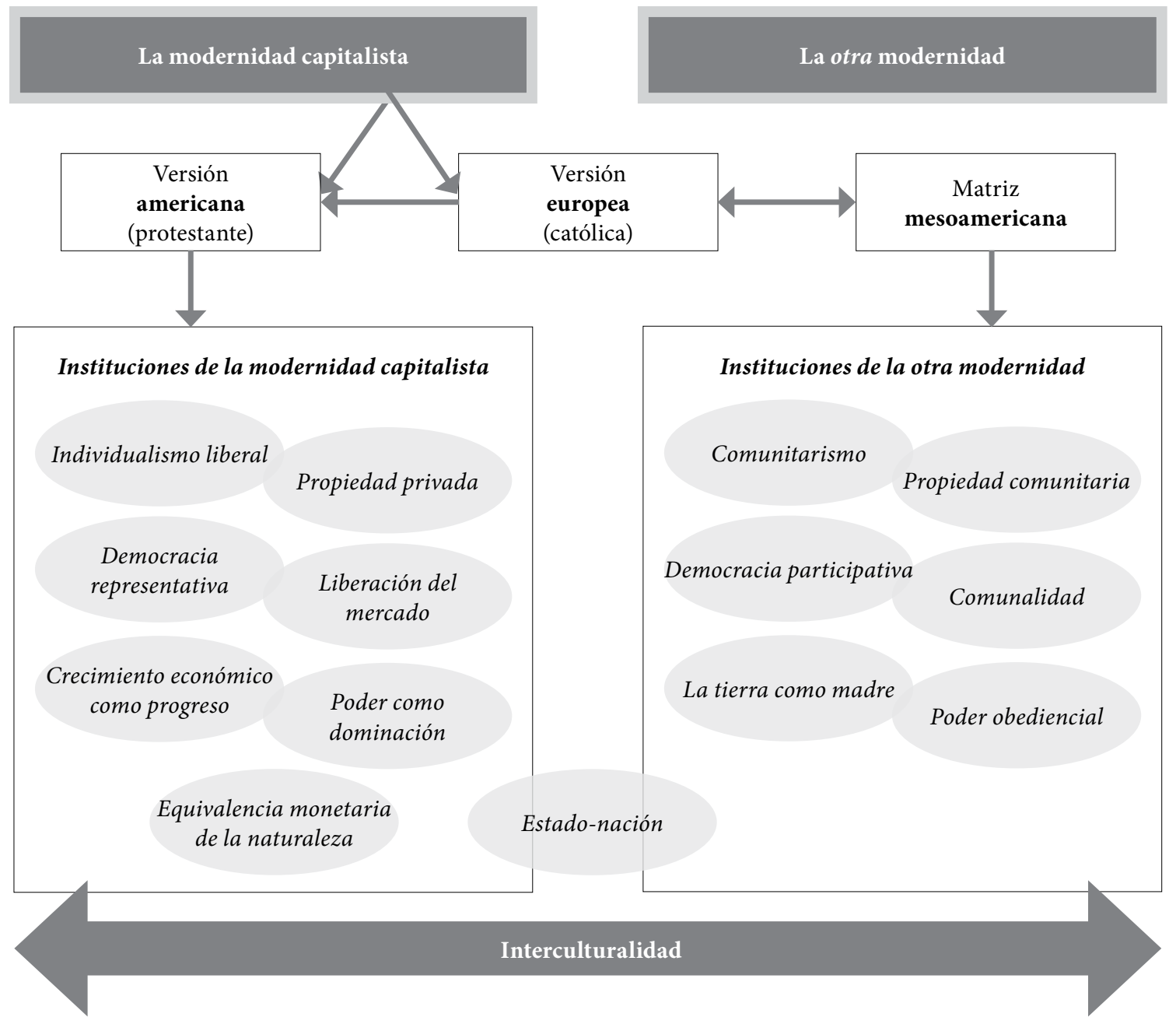

Fuente: Elaboración propia.

desde la comunidad "para seguir perteneciendo a ella". Se expresa a través de una diversidad de actividades, entre éstas: la asamblea para la decisión, el cargo para la coordinación, el tequio para la construcción y la fiesta para el goce (Martínez Luna, 2003).

- La posesión territorial comunitaria no sólo es factor de cohesión social basada en el bien común definido cultural e históricamente - como puede ser la tenencia de la tierra comunal-, sino también es fundamental por la preservación del espacio vital. Como la base territorial para la transformación, la expresión de los conocimientos específicos sobre la utilización de los recursos naturales y como la base material para la autonomía política y productiva. 
- La cosmovisión, en la que se agrupan y se exploran todas aquellas manifestaciones sobre la percepción cultural de la naturaleza. Por ello su trascendencia en la indagación para relacionarla con los procesos de apropiación social de la naturaleza.

La comunalidad no es la representación conjunta de los intereses individuales sobre los colectivos, como sucede en la noción de "contrato social" de Hobbes o de Locke. No se entiende como:

un convenio [donde] cada quien hacía el contrato para resguardar su interés particular; si el contrato, la asociación política, no lo resguardaba, me siento con todo el derecho de ir en contra porque acepté el contrato en función de mi interés egoísta, y si no responde a él, me rehúso a continuarlo (Villoro, 2003: 48-49).

En el caso de las citadas praxis campesinas se puede entender como un contrato en el que:

puesto que lo acepto buscando el bien de todos por medio de la voluntad general, aunque vaya en contra de mi interés personal, seguiré fiel el contrato... La democracia es, en este segundo tipo de contrato, una asociación política que a la vez, necesariamente, es ética, porque es la manera de mantener una entidad pública que garantice la libertad de todos, y que sea, por lo tanto, garante de autonomía (Villoro, 2003: 49).

Estas características serán fundamentales para enfrentar los procesos de las concesiones forestales y su superación.

\section{LAS CONCESIONES FORESTALES COMO EXCLUSIÓN: RESPUESTAS DE LAS COMUNIDADES DE LA SIERRA NORTE DE OAXACA}

Inmersa en el inicio del proceso del modelo de la industrialización por sustitución de importaciones y dada la necesidad de reactivar la producción de celulosa, una reforma en la Ley Forestal de 1940 permitió un nuevo mecanismo de aprovechamiento forestal: las concesiones forestales por medio de empresas privadas llamadas Unidades Industriales de Explotación Forestal (UIEF). Así, con base en un decreto de 1956, se otorga una UIEF a la empresa privada de capital canadiense Fapatux. La concesión fue por 25 años y abarcaba 251823 hectáreas de bosques templados de la Sierra Norte de Oaxaca (Alatorre, 2000: 57).

En 1964, a raíz de su bancarrota, la empresa se transformó en paraestatal. Las pérdidas económicas y el deterioro ambiental estaban subordinados a mantener el modelo de industrialización por sustitución de importaciones. A principios de la década de 1970 se pone en práctica un plan para disminuir el problema financiero que consistía en "buscar la manera en que la fábrica recibiera la materia prima necesaria sin ninguna interrupción, y que ésta llegara con el precio más bajo" (Chapela, 1999: 106). Las respuestas campesinas ante el grado de explotación de los recursos forestales y la arbitrariedad de los criterios en la distribución de los beneficios llegan a su clímax apenas entrada la década de 1980. En estas circunstancias, la tensión entre los conflictos económicos distributivos se liga como actos de injustica derivados del poder político del gobierno federal. Tomando de referencia el enfoque de la ética concreta de Villoro (2007), que apunta aproximarse al tema de la justicia desde su vía negativa, a continuación se aborda este asunto desde un acercamiento analítico de las estrategias campesinas heterogéneas para "escapar del poder injusto" generado por y desde la figura de las concesiones forestales. Para ello se identifican y describen tres momentos.

\section{Primer momento. La exclusión como experiencia de carencia}

En esta fase hay un primer reconocimiento de un daño causado, ya sea por omisión o por acciones de "los otros", de quienes no pertenecen al grupo carente. ${ }^{10}$

\footnotetext{
${ }^{10}$ Daño no es sólo falta, necesidad no satisfecha, es también sufrimiento causado por un agente. Agente de daño es el otro. Puede
} 
Entonces el grupo agredido cobra conciencia, primero a nivel individual, de que es el portador causado de ese daño por el grupo dominante. Desde la "experiencia individual" se percibe que hay un rechazo o una relegación respecto de otro grupo con el cual tiene contacto. Aquí emerge la sensación de exclusión:

No se trata de un rechazo en general sino de una relación vivida en el seno de la sociedad concreta. En efecto, ser excluido es no formar parte de la totalidad al igual que cualquier otro, no ser reconocido plenamente en totalidad, no tener un sitio en ella igual que los demás, justamente por ser diferente. Así, la conciencia de identidad del carente está ligada a su conciencia de ser diferente y ésta a su experiencia de exclusión (Villoro, 2007: 22).

Entre los procesos de estas "carencias" en las comunidades citadas como referentes empíricos se enumeran las siguientes identificadas en el trabajo etnográfico y referidas por Keuze, Pérez y Cervantes (1984), las cuales presentan cierta secuencia cronológica:

a) La falta de empleo. Durante los primeros años de explotación la Fapatux no utilizó la mano de obra disponible en la región, sino que trajo personal ya adiestrado en esas tareas proveniente del estado de Michoacán. Conforme hubo mayor capacitación se fueron dando espacios laborales a los comuneros para corte, troceo y extracción, así como una pequeña participación en el transporte. A finales de los años setenta, las fuentes de trabajo ofrecidas para toda la región eran de aproximadamente 4 mil comuneros como cortadores de madera (Keuze, Pérez y Cervantes, 1984).

b) Las demandas laborales: salario y condiciones de trabajo. Los riesgos y malas condiciones de trabajo para los comuneros fueron altos, y con frecuencia

personalizarse, pero también concebirse como un sujeto vago, indeterminado e impersonal, como "la sociedad", "el sistema", "la clase dominante", "los otros". En suma, los que no son como nosotros, los que no comparten la misma ausencia de valor (Villoro, 2007: 20-21). se registraron accidentes, cortaduras o machucones. A finales de la década de 1980 eran patentes los bajos salarios, la ausencia de prestaciones, el mal trato, el mal servicio, los altos descuentos del seguro social y la prolongación de la jornada de trabajo (Keuze, Pérez y Cervantes, 1984).

c) Trabas burocráticas e inadecuados pagos del "derecho de monte". El pago era depositado y administrado por el Fideicomiso del Fondo Nacional de Fomento Ejidal (Fifonafe), con difícil acceso a los miembros de las comunidades agrarias, además de que la burocracia de la Secretaría de Reforma Agraria (SRA) funcionaba como la gestora de las comunidades agrarias. Así, aparte del Fifonafe, la SRA seguía controlando fuertemente todos los órdenes administrativos y la toma de decisiones para la obtención de permisos. En 1978 se cambió al Banco Ejidal para Fondos Comunes y se propuso una distribución diferente de la renta a las comunidades. Sin embargo, la División Forestal seguía de intermediaria entre la Fapatux y cada una de las comunidades, lo cual dificultaba las negociaciones. Por ejemplo, el dinero que se designaba directamente a la comunidad para utilizarse en obras de carácter social tenía que pasar por una autorización del Fideicomiso. Por otra parte, las comunidades empezaron a sospechar que el proceso del cálculo de extracción de madera no era el correcto. Sin posibilidades de negociar los contratos anuales, éstos se basaban en un concepto de la renta de su bosque por unidad de metro cúbico de madera que se entregaba a la fábrica. Se desconocía la forma y el monto a calcular para cada unidad.

d) Los servicios técnicos forestales. El aprovechamiento implicaba la contratación de técnicos forestales, pero ellos estarían en función de los requisitos que el estado dispone. La ley no distinguía requerimientos industriales o de las condiciones campesinas.

e) La imposibilidad del uso y usufructo del territorio: la negación al desarrollo en el plano de 
bienestar. En este nivel se refleja un nivel de identificación del motivo de exclusión más general y articulador. La cercanía con la fecha del vencimiento de la concesión permitió identificar más claramente este acto de uso del poder injusto. La negación de su territorio, significaba, entonces, la negación para el desarrollo de su cultura, su forma de subsistencia.

Entonces era indispensable enfrentar los procesos de exclusión ante demandas de salud, educación, resolución de conflictos agrarios, industrias forestales y caminos rurales, entre otras cosas. Como se pudo observar, los ámbitos de la exclusión pueden ser diversos, complejos y mutuamente interrelacionados: lo económico percibido primeramente como desempleo, luego en la explotación laboral, pasando por la desigual distribución de bienes; en lo político, manifestado en la falta de participación en las instancias de decisión concentradas en las oficinas de la SRA y el control sobre su estructura organizativa; en lo jurídico, al desplazar "legalmente", pero ilegítimamente, su derecho a realizar sus procesos de apropiación social de la naturaleza en sus territorios. En otra fase del proceso destaca lo ambiental. Hay otros aspectos de exclusión, que en este proceso descrito no se advierten claramente, como lo étnico y el género. Así, desde estos procesos se presentan dos visiones de justicia por parte del grupo excluido: una, la presentada y aceptada por el consenso social; $y$ otra, la percepción de una carencia como un acto de injusticia.

\section{Segundo momento. El territorio y la equiparación con el excluyente}

Ante la experiencia de la exclusión como injusticia, el grupo puede manifestar dos posturas: la aceptación pasiva o su rechazo. El rechazo implica un disenso contra el poder impuesto, y su traducción operativa, y de la noción de identidad - por la exclusión- se convierte en movimiento social del grupo agredido, movilización contra el poder generador de injusticia. Es una confrontación de poderes que ocurrió en diferentes fases en la Sierra Norte de Oaxaca, como sucedió, por ejemplo, con las huelgas por mejores condiciones laborales y de comercialización y pago adecuado de la madera. Son procesos importantes, aunque no constituyen la esencia de la identificación significativa de la exclusión.

El punto culminante de la identificación del mayor grado de exclusión es la caracterización de la demanda sobre el territorio. En esa solicitud se sintetizan todas las demás demandas, y se consolidan como un elemento fuertemente aglutinador y equiparador con el excluyente. Las respuestas del gobierno mexicano fueron evasivas con el punto central de la demanda, por ello se instrumentaron una serie de estrategias corporativistas y evasivas, sobre todo a partir de la SRA. Esta demanda decantó formalmente en pleno festejo del natalicio del Benemérito de las Américas en Guelatao, Oaxaca, en 1980. El presidente municipal de Guelatao, Víctor García, en el acto protocolario frente al gobernador del estado, el general Jiménez Ruiz, expresó abiertamente la exigencia de 28 comunidades: la no renovación de la concesión forestal (Martínez Luna, comunicación personal, 1 de julio, 2009). En este punto se dieron dos actos contra el poder injusto: a) el nivel de solidaridad dio pauta a la emergencia de un nivel de identidad comunitaria, y éste a uno de escala regional, estatal y nacional, y b) se da una ruptura contra el poder político formal, lo cual se convierte en una muestra de contrapoder. Aquí la noción de controversias y resistencia en la acción social y política adquiere sentido como respuesta ante el consenso efectivo, y se constituye en la primera forma para escapar del poder.

Días después, la acción social y política adquiere nombre y organización eficaz, se traduce en un nivel de organización con fuerte articulación y legitimación. Emerge la Organización de la Defensa de los Recursos Naturales y el Desarrollo Social de la Sierra Juárez (Odrenasij). Esta organización se erige como un ejemplo de poder obediencial en el sentido 
empelado por Dussel (2006a), es decir, como el lugar del ejercicio delegado del poder (potestas), como mediación, pero no como el lugar del poder, sino de su factibilidad. Ésta corresponde a una razón instrumental; es la necesidad de los medios para la defensa de la voluntad de vida, demanda plasmada en la recuperación de los bosques por parte de los pueblos de la Sierra Norte de Oaxaca. La demanda de la Odrenasij era integral. De esta forma se pasa a otro nivel fundamental para escapar del poder injusto: "de la experiencia del rechazo sufrido a la equiparación con el rechazante. Conciencia de equivalencia entre ambos e impulso consiguiente de equiparamiento con el otro" (Villoro, 2007: 24).

En esta equiparación con el otro - que excluyesucedieron combates en diferentes niveles, siendo uno de ellos el uso de la palabra desde la cual defiende y trata de justificar su disenso. La interpelación ${ }^{11}$ de las comunidades, a través de Odrenasij, se hizo presente. Las acciones fueron tanto de defensa y protección ante las agresiones del "otro", así como para pedir cuentas al Estado mexicano por sus agresiones manifestadas en la concesión forestal. Con esta equiparación explícita con el agresor se presentan dos vías: la ruptura o el deterioro de la comunicación. Esto se resuelve en el siguiente momento.

\section{Tercer momento. El reconocimiento del otro: la derogación de la concesión forestal}

En esta fase hay un doble movimiento simultáneo: por una parte, el excluido manifiesta y afirma su diferencia, pero al mismo tiempo proclama su igualdad en relación con el oponente. La demanda de la Odrenasij es clara y directa frente al gobierno federal. La orientación de la lucha definida por la organización se da en un plano político y jurídico. En un plano de demanda de justicia social y de una forma de autonomía, pues las comunidades plantean un programa

\footnotetext{
${ }^{11}$ Dussel (2006a) indica que la "interpelación" del excluido se reali-
} za desde quienes se consideran fuera del orden de normas vigentes. integral de desarrollo a partir de la recuperación de su territorio. En palabras de Villoro:

Es un paso en el establecimiento posible de valores y normas comunes. Pero serían normas que no decretarían ninguna uniformidad entre los adversarios, sino abriría la posibilidad de reconocimiento recíproco de una igualdad en la facultad de acceder a valores comunes, sin eliminar las diferencias (Villoro, 2007: 33).

Es decir, los comuneros se asumen como un segmento de la sociedad mexicana - ciudadanosque tiene el derecho, al igual que los otros, a disponer de su territorio para realizar los procesos de apropiación social de la naturaleza que ellos determinen. El "otro" es el mismo Estado mexicano, el cual tiene dos opciones: el reconocimiento de ese derecho a estos ciudadanos o su negación. En el segundo caso, la negación de ese derecho es interpretada como una exclusión, con la consiguiente generación y aumento del disenso. La decisión es tomada en los últimos días del saliente gobierno federal: se renueva la concesión. ${ }^{12}$ Es decir, no hay un reconocimiento del "otro", del gobierno federal a las demandas de las comunidades. Ante un acto de no equiparación del excluyente, manifestado en la continuación de la concesión forestal, la movilización se intensifica. Ello genera un fuerte disenso en la sociedad:

Pero las organizaciones sociales que habían emergido en los años previos tuvieron la capacidad para interponer un recurso de amparo contra el decreto; es decir, en contra del presidente de la república y en contra del secretario de Agricultura. Y no sólo eso, el decreto de ampliación de la concesión aglutinó a las comunidades de la Sierra Norte y Sierra Sur, formándose un frente de más de 30 comunidades que integran la Odrenasij, así como de otras comunidades. La organización social adquirió una dimensión estatal.

${ }^{12}$ Diario Oficial de la Federación, decreto que establece una Unidad de Ordenación Forestal en el Estado de Oaxaca, México, D. F., Secretaría de Agricultura y Recursos Hidráulicos, 26 de noviembre de 1982. 
En el nivel regional se formaron otras organizaciones en defensa de los recursos naturales, como la Coordinadora para el Desarrollo Rural en la Zona Mixe (Codremi), o la Unión de Comunidades Indígenas de la Zona Norte del Istmo (Ucizoni). En todos los casos había una amalgama de organizaciones comunitarias, organizaciones regionales y grupos universitarios de asesoría, que en conjunto estaban planteando que era posible un desarrollo en el que se desarrollaran nuevas relaciones de producción, más allá de los esquemas ya probados de manejo individual-privado o manejo estatal de los bosques (Chapela, 1999: 107-108).

El reconocimiento del "otro" fue una larga lucha. Como era de esperarse, la acción de las organizaciones sociales era percibida como un desafío al estado de derecho. El instrumento jurídico de amparo, parte fundamental del mismo sistema de normas, ahora es interpretado por un segmento de la sociedad como un acto contra el orden público. La exigencia de Odrenasij y sus comunidades no se entendía como un acto de reclamo ante el poder injusto, no fue comprenel sector forestal de Oaxaca, sino que fue interpretada por los sectores más conservadores casi como un atentado al orden público" (Chapela, 1999: 108).

La equiparación del excluido - las comunidades forestales - con el agresor - el gobierno mexicano- significa una reivindicación de un derecho. Este derecho es la demanda de reconocimiento por los otros en la pretensión de sus exigencias: la no renovación de la concesión forestal. Como se señaló, esto puede resultar en dos alternativas: el conflicto entre uno y otro grupo o la reivindicación del derecho entre ambos. El caso de la defensa de los recursos naturales en la sierra incluyó ambos aspectos. Con la renovación de la concesión forestal el disenso creció fuertemente. El país en general y la sociedad rural estaban en una fase crucial: una política coyuntural y otra estructural. López Portillo dejaba la presidencia, pero con ello también una fuerte crisis económica y un ambiente de conflicto social, pero a la vez el Poder Ejecutivo era asumido por un grupo de tecnócratas con un proyecto económico

identificado con el neoliberalismo impulsado desde la visión del Fondo Monetario Internacional. En esta coyuntura política e inicio de una fuerte ofensiva de cambio estructural, el gobierno federal decide cancelar el decreto. Es desde esta perspectiva que emerge la noción del reconocimiento del otro como una ética concreta que establece los límites de su cumplimiento efectivo en hechos históricos concretos, y no en normas que deban cumplirse. Como lo indica claramente Chapela (1999), a partir de la no renovación de las concesiones forestales a mediados de la década de 1980 se da cabida a una tercera vía en la silvicultura: ni estatal, ni privada, sino en manos de las comunidades, contando con la experiencia e infraestructura acumulada durante los procesos de las concesiones forestales.

\section{DESPUÉS DE LAS CONCESIONES FORESTALES...}

La Odrenasij desaparece después de la recuperación de los bosques, pero al interior de cada comunidad, al convertirse en permisionarias del aprovechamiento de su propio bosque, se produjo una dinámica de organización cualitativamente diferente. Así, el impacto del movimiento en la Sierra Norte de Oaxaca fue muy heterogéneo, pero en gran parte de las comunidades contribuyó a una reconfiguración de la comunalidad ligada a una forma de realizar los procesos de acumulación de modo alterno a la racionalidad guiada por las concesiones forestales. En este sentido, la transformación de las lógicas generadoras de conflictos económicos distributivos fue posible por la modificación de las lógicas de acumulación impuestas. La nueva dinámica dada en éstas y otras comunidades forestales favoreció la emergencia de un nuevo ethos comunitario (Garibay, 2007), pero también el desarrollo de procesos de generación de excedentes con una mayor responsabilidad social y ambiental (Fuente, 2009), integrados por las siguientes características: 
- El desarrollo de las fuerzas productivas comunitarias. ${ }^{13}$ Las comunidades han ampliado y desplegado sus fuerzas productivas no sólo al interior del aprovechamiento forestal, pues se han diversificado a otras esferas productivas, de servicio, comerciales y a la llamada "pluriactividad” (Barkin y Rosas, 2006). Este fenómeno se relaciona a su vez con la aplicación de procesos productivos más eficientes - energética, material y financieramente- y generadores de mayor "valor comercial", como lo representa por ejemplo la transformación de procesos forestales únicamente de extracción de madera a otros como la elaboración de muebles.

- La diversificación del mercado. Implica diversificación de las "mercancías", productos o servicios, pero también de las opciones de potenciales consumidores de éstos. Asimismo, involucra la posibilidad de la diversificación productiva -empresas ecoturísticas, plantas de purificación de agua, tiendas comunitarias, etc.-. En el fondo, se trata de poner en marcha procesos alternativos ante las esferas del intercambio y de la circulación fuera de las acciones azarosas del mercado y de la proletarización. La esfera del comercio justo, basado en una economía solidaria, forma parte de una de las estrategias importantes en la diversificación del mercado.

- La formación de redes de apoyo. Incluye la interacción de diversas instancias de la sociedad civil y de instituciones de educación y desarrollo tecnológico. Una de las vinculaciones de las redes de apoyo es su contribución en el desarrollo (y conservación) de las fuerzas productivas co-

\footnotetext{
${ }^{13}$ Habrá que señalar, no obstante, que la generación de excedentes a partir de un desarrollo de las fuerzas productivas comunitarias presenta contradicciones, por ejemplo la que se hace patente cuando a un crecimiento de la producción no corresponde una adecuada ampliación del consumo, o que una de sus variantes es el requerimiento de una mayor cantidad de insumos energéticos y materiales. De ahí la importancia de instrumentar un sistema productivo en el que se concilie el desarrollo de las fuerzas productivas desde una economía neguentrópica.
}

munitarias, tanto las ambientales como las que se expresan en el desarrollo tecnológico y los grados de apropiación en este ámbito.

Estas características denotan una nueva forma de responsabilidad social, pero también ambiental. En las comunidades forestales de la Sierra Norte de Oaxaca analizadas se muestra una participación en el diseño de políticas de apropiación social de la naturaleza en que sobresalen las actividades de conservación, restauración y ordenamiento, y no sólo las de aprovechamiento. Así lo constata el activo involucramiento de las comunidades abordadas en los procesos del Consejo de Administración de Bosques (Forest Stewardship Council, FSC por sus siglas en inglés), que les permite obtener una certificación de un manejo silvícola con atributos de sustentabilidad — sociocultural, económica y ambiental- y beneficios económicos. Llama la atención, sin embargo, una aparente correlación entre el grado de desarrollo silvícola y el decrecimiento en los procesos de desarrollo de actividades agrícolas vinculadas con la autosuficiencia alimentaria. No obstante, este desarrollo forestal ha favorecido varios aspectos: disminución de la migración, la diversificación productiva y el fomento de una inversión pública hacia servicios e infraestructura de las localidades.

El movimiento de la Sierra Norte de Oaxaca formó parte de una movilización estatal y nacional mayor, y contribuyó como contrapeso en la coyuntura política y estructural del país en materia de política forestal. Cabe mencionar el acercamiento, asesoría y solidaridad de la Tosepan Titataniske, tal como se recordó en el "Segundo Taller Revisión Retrospectiva del Desarrollo de la UZACHI" celebrado en octubre de 2008. Esta movilización dejó su huella en la formulación de la Ley Forestal de 1986, en la que se cancelaba el modelo de concesión forestal, pero también la posibilidad de que las comunidades tuvieran la titularidad de los servicios técnicos forestales. Ambos son aspectos clave para explicar, en parte, el desarrollo de la silvicultura comunitaria en México. Esta cultura forestal comunitaria también fue capaz 
de amortiguar el desenfreno neoliberal de poner en el centro de la política forestal las plantaciones forestales comerciales. Especialmente en el debate dado en la reforma de ley de 1997, en la que se bloqueó la propuesta de autorización de plantaciones forestales comerciales en terrenos forestales, con sus consiguientes consecuencias ambientales y sociales.

\section{A MANERA DE CONCLUSIONES}

El tema de las concesiones y la exclusión social en comunidades con ascendencia en la cultura mesoamericana de la Sierra Norte de Oaxaca se manifiesta en formas heterogéneas, en función de los diferentes calendarios y contextos geopolíticos. Con las primeras empresas privadas forestales se introduce la idea de la "modernización" de los sistemas de explotación forestal, en que la cultura "tradicional" de la Sierra Norte de Oaxaca es una manifestación de "atraso, de rezago", que habrá de civilizar. Con la intervención de la empresa paraestatal, y en el contexto de los ideales de la Revolución Mexicana, se impulsa un proyecto de nación en el que el Estado reconoce a la comunidad campesina, pero dentro de una modernidad "nacionalista" en la que la cultura y recursos naturales habrán de integrarse. ${ }^{14}$ Este proceso se constituye en un referente analítico para explicar parte de las actuales estrategias que aplican varios pueblos de dicha región en sus procesos de apropiación de los recursos forestales, aunque también para identificar el papel que desempeñó la reconfiguración de su organización comunitaria como respuesta ante los procesos de exclusión inherentes a las concesiones forestales.

Las enseñanzas de esta lucha pueden advertirse en diversos niveles. Desde una perspectiva epistémica, la categoría de comunalidad aparece como

\footnotetext{
${ }^{14}$ De ahí la función de los primeros profesores de primaria que llegan a la Sierra Norte de Oaxaca que, entre otros aspectos, se manifiesta en su prohibición al uso de la lengua indígena.
}

una institución fundamental de tal reconfiguración comunitaria. Si bien, por otro lado es política: ante los fuertes procesos de exclusión social, la comunalidad se observa como una estrategia - entre otraspara promover un proceso de construcción de nichos de sustentabilidad en comunidades rurales, en el que la interculturalidad, la equidad y la justicia distributiva se constituyen como atributo ético fundamental de la sustentabilidad. Al mismo tiempo, estas praxis muestran que en la medida en que la intervención del Estado se manifiesta de manera autoritaria o violenta genera disenso social, pero a su vez cataliza las respuestas organizadas de los grupos sociales que logran identificar que han sido excluidos como ciudadanos.

En esta tesitura, las respuestas de las comunidades aglutinan una amplia gama de orientaciones y direcciones. Con todo, se mantiene la idea de que si estas réplicas campesinas logran transformar las lógicas desde las que ocurren los conflictos económicos distributivos, también repercuten en una nueva conformación social y en los modos de realizar los procesos de apropiación social de la naturaleza, y por tanto de construcción de una sustentabilidad. Hoy, con el neoliberalismo, el tema de la exclusión y las concesiones - como el de las mineras - se ha exacerbado. En este nuevo entorno, el papel desempeñado por el Estado mexicano en su proceso de modernización ha puesto el énfasis en el crecimiento económico, pero no en la justicia distributiva ni en la responsabilidad ambiental. Ello puede manifestarse en un disenso social.

Hay que destacar, además, que estas praxis campesinas no son estáticas. Requieren cotidianamente la construcción de espacios autonómicos, los cuales son frágiles y demandan su constante reconfiguración en función de las señales de las instituciones de la racionalidad económica de corte neoliberal: el Estado y el mercado. Su configuración implica el enfrentamiento de diversas luchas políticas no sólo al exterior, sino al interior de las mismas comunidades. Estas luchas ocurren actualmente en la Sierra Norte de Oaxaca y en diversos ámbitos de 
la sociedad rural. Por ello se considera fundamental recuperar y revalorar las contribuciones de aquellas generaciones de comuneros en la construcción de la comunalidad y la sustentabilidad como una herencia frágil.

No se pretende hacer una apología de la cultura de los pueblos originarios, pues el trabajo procuró distanciarse de las premisas de un "relativismo cultural fuerte". Se reconoce que si bien todas las culturas son respetables, no todas promueven valores y prácticas culturales de equidad y de justicia hacia su grupo. El enfoque de clases y de una multiculturalidad crítica es una aspiración compleja deseada a lo largo del trabajo. Más bien, es una invitación analítica a interpretar y escuchar otras voces en la conformación de nuevos escenarios socioambientales; voces para un diálogo de saberes (Leff, 2004, 2006). Así, frente a la concepción única de modernidad o posmodernidad como visión americanizada, el trabajo se inscribe en la posibilidad de una transmodernidad e interculturalidad (Dussel, 2006b), o de una modernidad alternativa (Toledo, 2000). Las culturas amerindias forman parte de este concierto, proporcionan estrategias alternas para la construcción de otros mundos posibles.

\section{Bibliografía}

Alatorre, Gerardo, 2000, La construcción de una cultura gerencial democrática en las empresas forestales comunitarias, Procuraduría Agraria, Casa Juan Pablos, México.

Barkin, David, 1998, Riqueza, pobreza y desarrollo sostenible, Jus, Centro de Ecología y Desarrollo-Centro Lindavista, México, en línea: <http://anea.org.mx/docs/ Barkin-Sostenibilidad.pdf $>$.

— , 2008, "Introducción: economía ecológica", en Argumentos: Estudios Críticos de la Sociedad, vol. XXI, núm. 56, pp. 7-15.

y Mara Rosas, 2006, “¿Es posible un modelo de acumulación alternativo?", en Revista Polis, vol. V, núm. 12, Chile, en línea: <http://www.revistapolis. cl/13/ind13.htm>, consultado el 26 de agosto de 2009.
Boege, Eckert, 2009, Patrimonio biocultural de los pueblos indígenas de México: hacia la conservación in situ de la biodiversidad y agrodiversidad en territorios de los pueblos indígenas, Instituto Nacional de Antropología e Historia, Consejo Nacional para el Desarrollo de los Pueblos Indígenas, México.

Bonfil Batalla, Guillermo, 2005, México profundo. Una civilización negada, Random House Mondadori, México.

Bray, David, 1995, "Peasant Organizations and the Permanent Reconstruction of Nature: Grassroots Sustainable Development in Rural Mexico", en Journal of Environment and Development, vol. IV, núm. 2, pp. 185-204.

, Leticia Merino, Patricia Negreros, Gerardo Segura, Juan Manuel Torres y H. F. M. Vester, 2003, "Mexico's Community-Managed Forests as a Global Model for Sustainable Landscapes", en Conservation Biology, vol. XVII, núm. 3, pp. 672-677.

, Leticia Merino y Deborah Barry (eds.), 2007, Los bosques comunitarios de México. Manejo sustentable de paisajes forestales, Secretaría de Medio Ambiente y Recursos Naturales, Instituto Nacional de Ecología, Instituto de Geografía-Universidad Nacional Autónoma de México, Consejo Mexicano para la Silvicultura Sostenible, Florida Internacional University, México.

Burkett, Paul, 2006, Marxism and Ecological Economics. Toward a Red and Green Political Economy, Brill, Danvers. una perspectiva histórica de la jerarquía cívico-religiosa mesoamericana”, en Antropología, Boletín Oficial del Instituto Nacional de Antropología e Historia, núm. 14.

Chapela, Francisco, 1999, "Emergencia de las organizaciones sociales de Oaxaca: la lucha por los recursos forestales", en Alteridades, vol. XVII, núm. 9, pp. 105-112.

Comisión Nacional Forestal (Conafor), 2008, "Acerca de la Conafor", en México Forestal, núm. 82, 14-27 de abril, revista electrónica: <http://www.conafor.gob. $\mathrm{mx}>$, consultado el 26 de agosto del 2009.

Costanza, Robert, John Cumberland, Herman Daly, Robert Goodland y Richard Norgaard, 1999, Una introducción a la economía ecológica, CECSA, México.

Cruz Martínez, Ángeles, 2007, "Operación minera en Oaxaca acaba con manantiales de la zona", en La Jornada, 7 de octubre, en línea: <http://www.jornada.unam. $\mathrm{mx} / 2007 / 10 / 07 /$ index.php?section $=$ sociedad $\&$ article $=$ 036n1soc $>$, consultado el 26 de agosto de 2009.

Díaz, Floriberto, 2007, “Comunidad y comunalidad", en Sofía Robles y Rafael Cardoso (comps.), Floriberto Díaz Comunalidad, energía viva del pensamiento, Universidad Nacional Autónoma de México, México, pp. 34-50. 
Dussel, Enrique, 2006a, 20 tesis de política, Siglo XXI, Centro de Cooperación Regional para la Educación de Adultos en América Latina y el Caribe, México.

— 2006b, Filosofía de la cultura y la liberación, Universidad Autónoma de la Ciudad de México, México.

Echeverría, Bolívar (comp.), 2008, La americanización de la modernidad, Universidad Nacional Autónoma de México, Era, Centro de Investigaciones sobre América del Norte, México.

Foladori, Guillermo, 2005, "Una tipología del pensamiento ambientalista", en Guillermo Foladori y Naína Pierri (coords.), Desacuerdos sobre el desarrollo sustentable, Universidad Autónoma de Zacatecas, Miguel Ángel Porrúa, Cámara de Diputados, México.

Fuente Carrasco, Mario, 2008, "La economía ecológica, ¿un paradigma para abordar la sustentabilidad?", en Argumentos, vol. XXI, núm. 56, pp. 75-99.

_ 2009, "Nueva ruralidad comunitaria y sustentabilidad: contribuciones al campo emergente de la economía ecológica", en Revista Iberoamericana de Economía Ecológica, vol. XIII, pp. 55-69, en línea: <http://www.redibec.org/IVO/rev13_04.pdf>.

Garibay, Claudio, 2007, "El dilema corporativo del comunalismo forestal", en Desacatos. Revista de Antropología Social, núm. 23, pp. 251-274.

1104 Hernández-Díaz, Jorge (coord.), 2007, Ciudadanías diferenciadas en un Estado multicultural: los usos y costumbres en Oaxaca, Siglo XXI, Universidad Autónoma Benito Juárez de Oaxaca, México.

Keuze, P., F. Pérez y A. Cervantes, 1984, "El bosque y las comunidades indígenas: el caso de la Sierra Juárez, Oaxaca", en Amalia Muñoz Rocha (coord.), Jornada El Campo y el Campesino: Producción y Hambre, Universidad Autónoma Metropolitana, México, pp. 177-183.

Klooster, Dan, 2000, "Institutional Choice, Community, and Struggle: A Case Study of Forest Co-Management in Mexico", en World Development, vol. XXVIII, núm. 1, pp. 1-20.

Leff, Enrique, 2004, Racionalidad ambiental. La reapropiación social de la naturaleza, Siglo XXI, México.

- 2006, Aventuras de la epistemología ambiental. De la articulación de las ciencias al diálogo de saberes, Siglo XXI, México.

Lockhart, James, 1985, Los nahuas después de la Conquista, Fondo de Cultura Económica, México.

Martínez Luna, Jaime, 2003, Comunalidad y desarrollo, Consejo Nacional para la Cultura y las Artes, Centro de Apoyo al Movimiento Popular Oaxaqueño, A. C., México.

- 2009, Entrevista con Jaime Martínez Luna, expresidente de la Odrenasij, Guelatao de Juárez, Oaxaca, 1 de julio.

, 2010, Eso que llaman comunalidad, Consejo Nacional para la Cultura y las Artes, Centro de Apoyo al Movimiento Popular Oaxaqueño, A. C., Fundación Harp Helú, Secretaría de Cultura de Oaxaca, México.

Martínez Alier, Joan, 2004, El ecologismo de los pobres. Conflictos ambientales y lenguajes de valoración, Icaria, Antrazyt, Facultad Latinoamericana de Ciencias Sociales, Barcelona.

Mitchell, Ross E., 2008, "El ejercicio de la democracia en dos comunidades forestales de la Sierra Norte de Oaxaca", en Desacatos. Revista de Antropología Social, núm. 27, pp. 149-168.

Morales Loo, María Antonieta, 2006, ¿De quién es la responsabilidad? Crisis y reconstrucción del espacio social, Taurus, Santillana, México.

Otero, Gerardo, 2004, ¿Adiós al campesinado? Democracia y formación política de las clases en el México rural, Miguel Ángel Porrúa, Universidad Autónoma de Zacatecas, Simon Fraser University, México.

Rawls, John, 1995, Teoría de la justicia, Fondo de Cultura Económica, México.

Sánchez Vázquez, Adolfo, 2003, Filosofía de la praxis, Siglo XXI, México.

Seara, Modesto, 1995, La hora decisiva. Análisis de la crisis global, Porrúa, México.

Sen, Amartya, 1997, Bienestar, justicia y mercado, Paidós, Instituto de Ciencias de la Educación, Universidad Autónoma de Barcelona (Pensamiento Contemporáneo, núm. 48), Barcelona.

Taylor, William B., 1972, Landlord and Peasant in Colonial Oaxaca, Stanford University Press, Stanford.

Toledo, Víctor M., 2000, La paz en Chiapas. Ecología, luchas indígenas y modernidad alternativa, Universidad Nacional Autónoma de México, Quinto Sol, México.

- y Narciso Barrera-Bassols, 2008, La memoria biocultural. La importancia ecológica de las sabidurías, Icaria, Barcelona.

Villoro, Luis, 2003, De la libertad a la comunidad, Fondo de Cultura Económica, Instituto Tecnológico y de Estudios Superiores de Monterrey, México.

— 2007, Los retos de la sociedad por venir, Fondo de Cultura Económica, México. 